\title{
Typing of methicillin-resistant Staphylococcus aureus isolates from Düsseldorf by six genotypic methods
}

\author{
F.-J. SCHMITZ*†, M. STEIERT†, H.-V. TICHY\$, B. HOFMANN*, J. VERHOEF†, H.-P. HEINZ*, \\ K. KÖHRERß and M. E. JONES†
}

*Institute for Medical Microbiology and Virology, Heinrich-Heine-Universität Düsseldorf, Universitätsstraße 1, Geb. 22.21, 40225 Düsseldorf, Germany, †Eijkan-Winkler Institute for Medical Microbiology, University Hospital Utrecht, The Netherlands, $\ddagger$ TÜV Südwest DLG, Abteilung Biologische Sicherheit, Mikrobiologisches und gentechnisches Labor, Freiburg, Germany and \$Molekularbiologisches Zentrallabor im BiologischMedizinischen Forschungszentrum der Heinrich-Heine Universität Düsseldorf, Germany

\begin{abstract}
Nosocomial infections caused by methicillin-resistant Staphylococcus aureus (MRSA) represent an increasing problem in hospitals. Quick and reliable typing methods are required to obtain information about the relatedness of MRSA isolates and to allow faster implementation of appropriate infection control measures. This investigation describes the distribution of MRSA isolates from 11 hospitals in the Düsseldorf region of Germany, and the ability of six different genotypic typing techniques - pulsed-field gel electrophoresis (PFGE), random amplification of polymorphic DNA (RAPD), 16S23S rDNA spacer amplification, protein A-gene PCR, PCR characterisation of the hypervariable region (HVR) adjacent to $m e c A$, and coagulase gene-PCR - to detect different unrelated types. Of 7814 S. aureus isolates tested, $489(6.3 \%)$ were MRSA, of which 183 were selected for subsequent molecular analyses on the basis of being the first MRSA isolated from colonised or infected patients. Larger hospitals had a higher incidence of MRSA and a greater variability in genotypes than smaller hospitals. All methods confirmed the presence of two main clonal types. The ability of techniques to detect different unrelated types was found to be as follows: PFGE, 28 types; 16S-23S rDNA spacer-amplification, 10 types; RAPD, nine types; protein A-gene PCR, five types; HVR-PCR, five types; and coa gene-PCR, two types. Combination of PFGE and one other PCR-based method (spacer-amplification, RAPD or protein-A gene PCR) provided the best resolution of types and allowed the identification of subtypes. Similar molecular types were identified with international MRSA isolates. Although PCR-based techniques have the advantage of rapid performance and easy handling, their discriminatory capacity is inferior compared to the more labour intensive PFGE.
\end{abstract}

\section{Introduction}

The rapid increase of methicillin-resistant Staphylococcus aureus (MRSA) as a cause of nosocomial infections, particularly in the intensive care setting and in immunocompromised patients, requires quick and reliable characterisation of strains and identification of clonal spread within hospitals. This enables the rapid implementation of appropriate infection control measures to contain hospital epidemics [1].

Received 20 March 1997; revised version accepted 12 August 1997.

Corresponding author: Dr F.-J. Schmitz.
DNA-based typing of bacterial strains is based on the principle that epidemiologically related bacterial isolates have genetic features that distinguish them from other epidemiologically unrelated strains [2]. Techniques used to type MRSA must be particularly discriminatory, as MRSA strains probably originate from a single clone or at least a few strain types [3], as genetic differences between MRSA isolates are minor compared to differences between MRSA and methicillin-sensitive $S$. aureus strains. Suitable typing procedures should combine typability of all (or most) isolates, reproducibility, good discriminatory potential, easily interpretable results and practicality.

Previously, MRSA isolates from different geographic areas were used to distinguish different types, enabling 
the identification of isolates of clonal origin [4-7]. As expected, these make significant differences between isolates and these differences seemed to be proof of good discriminatory potential of the method employed. In this investigation, all $S$. aureus isolates referred from peripheral hospitals within the Düsseldorf area were analysed. Six DNA-based typing methods were compared and critically appraised for their ability to assess the relatedness of selected MRSA isolates. These techniques included pulsed-field gel electrophoresis (PFGE), random amplification of polymorphic DNA (RAPD), 16S-23S rDNA spacer amplification, protein A-gene PCR, and PCR for the characterisation of the hypervariable region (HVR) adjacent to the $m e c \mathrm{~A}$ gene, and coagulase gene PCR. All these techniques are used routinely as tools for infection control purposes within the study hospitals. Furthermore, their practical use to characterise MRSA isolates during nosocomial outbreaks of infections was assessed. By combining typing techniques, attempts were made to determine subtypes, especially of the so-called North German epidemic MRSA strain, which is epidemic in Düsseldorf [8, 9]. An international collection of MRSA strains was also included in the typing study to assess the degree of relatedness of Düsseldorf MRSA-types to strains isolated internationally.

\section{Materials and methods}

\section{Strains and clinical setting}

Between 1993 and 1995, 7814 S. aureus isolates were referred to the Institute for Medical Microbiology at University Hospital, Düsseldorf, from 11 hospitals in the Düsseldorf area, ranging in size from 1500 to 200 beds. All were acute hospitals, none was a rehabilitation or chronic care nursing centre. Strains that were methicillin-resistant and 'first isolates' were selected for further genotypic characterisation. 'First isolates' are defined as MRSA isolated from any site of a colonised or infected patient on the first occasion. Additionally, 93 MRSA 'first isolates' from seven other countries - Japan (26 isolates), Brazil (21), Switzerland (11), Sri Lanka (5), Spain (13), the UK (14) and Hungary (3) - isolated during 1981-1989, kindly provided by Hoffmann La-Roche (Basel), were typed by RAPD, $16 \mathrm{~S}-23 \mathrm{~S}$ rDNA spacer amplification, protein-A gene PCR and HVR-PCR. The oxacillin MIC values for these strains were $32->1024 \mathrm{mg} / \mathrm{L}$. These 'international MRSA' were included to compare isolates circulating in the Düsseldorf region with those isolated internationally.

Identification of $S$. aureus isolates. The following criteria were used to confirm the identification of $S$. aureus isolates: production of catalase; tube coagulase (Bacto Coagulase Plasma EDTA-Test ${ }^{\circledR}$, Difco, Augsburg, Germany); nuclease (DNAase agar, Oxoid, Wesel, Germany); metabolism of mannitol anaerobically; and identification by a commercial biochemical identifica- tion system (API-Staph ${ }^{\circledR}$; bioMérieux, Nürtingen, Germany).

Coagulase-positive, methicillin-susceptible and methicillin resistant strains of $S$. aureus (ATCC nos. 12600, 13565, 19095, 25923, 29213, 33591, 33592 and 33593) and a coagulase-negative, methicillin-resistant strain of $S$. epidermidis (ATCC 27626) were used as controls.

Antibiotic resistance. Resistance to oxacillin was determined by a disk diffusion method (DIN 58940) [10] with oxacillin 5- $\mu \mathrm{g}$ disks (Becton Dickinson) on Mueller-Hinton-Agar, supplemented with $\mathrm{NaCl} 2 \%$ incubated for $48 \mathrm{~h}$ at $30^{\circ} \mathrm{C}$. Resistance was defined as a zone of inhibition of growth around the disk of $\leqslant 22 \mathrm{~mm}$.

\section{Pulsed-field gel electrophoresis (PFGE)}

The use of PFGE as the 'gold standard' in molecular epidemiology has been described previously by other authors [4, 11]. The GenePath Strain Typing System ${ }^{\circledR}$ (BioRad) was used as it has the advantage of being a fully standardised system with standardised reagents and electrophoretic programmes, potentially allowing greater reproducibility. The reproducibility of the PFGE results was assessed by using different individual colonies from the same isolate, which were then processed separately, introduced into DNA plugs and DNA fragments were resolved by PFGE. The intraassay and inter-assay reproducibility of the PFGE method were satisfactory in our laboratory. The derived PFGE patterns were analysed by GelCompar ${ }^{\circledR}$ software (UPGMA method). Isolates were considered to be unrelated if the percentage similarity of isolates was $<$ $80 \%$ instead of using criteria based strictly on the number of visible band differences. However, a value of $80 \%$ similarity usually corresponded to two-to-three band differences. MRSA subtypes were identified when isolates of the same PFGE-type were defined as different types by an alternative DNA-based typing method. Sub-types were considered epidemiologically unrelated with respect to infection control practices.

\section{Random amplified polymorphic DNA (RAPD)}

Genomic DNA from single bacterial colonies was extracted in $0.02 \mathrm{M} \mathrm{NaOH} / \mathrm{SDS} 0.1 \%$ at $90^{\circ} \mathrm{C}$ for $15 \mathrm{~min}$. After dilution with 10 -fold distilled water the cell fragments were centrifuged and $1 \mu \mathrm{l}$ was used as a template in each PCR reaction. A combination of $4 \mathrm{mM}$ $\mathrm{MgCl}_{2}, 10 \mathrm{mM}$ Tris/HCl (pH 8.3), $50 \mathrm{mM} \mathrm{KCl}, 200 \mu \mathrm{M}$ of each dNTP, 50 pmol of primer, BSA, $0.01 \%$, Taq Polymerase (Pharmacia) $1 \mathrm{U}$ and template DNA was used. A flourescently labelled oligonucleotide $5^{\prime}$ AATCGGGCTG-3', previously shown to successfully amplify strain-specific fragments $[12,13]$, was used to prime PCR amplifications. The target sequences were amplified in $25-\mu 1$ reaction volumes (after an initial 
denaturation step at $94^{\circ} \mathrm{C}$ for $2 \mathrm{~min}$ ) for 45 cycles $\left(94^{\circ} \mathrm{C}, 40 \mathrm{~s} ; 35^{\circ} \mathrm{C}, 40 \mathrm{~s}\right)$ followed by a final extension step at $72^{\circ} \mathrm{C}$ for $3 \mathrm{~min}$.

Amplified fragments were resolved with the A.L.F.System (Pharmacia). Strain relatedness was determined by the cluster analysis software (WinCam ${ }^{\mathbb{R}}$ 2.2) applying the Pearson algorithm, which considers both band position and intensities in the final analysis. This RAPD protocol is routinely used in this laboratory and has a well established record of reproducibility. Reproducibility of the RAPD protocol is checked routinely on the basis of obtaining identical banding patterns when processing different single colonies of the same isolate.

\section{S-23S rDNA spacer amplification}

Sample DNA preparation was the same as described previously for the RAPD protocol. Primer L1 (5'CAAGGCATCCACCGT-3') and the fluorescence-labelled primer G1 (5'-GAAGTCGTAACAAGG-3') were used to amplify the region between the $16 \mathrm{~S}$ rRNA gene and the $23 \mathrm{~S}$ rRNA gene by PCR as described previously [14]. A combination of $1.5 \mathrm{mM} \mathrm{MgCl}_{2}$, $10 \mathrm{mM}$ Tris/ $\mathrm{HCl}(\mathrm{pH} 8.3), 50 \mathrm{mM} \mathrm{KCl}, 200 \mu \mathrm{M}$ of each dNTP, 5 pmol of each primer, BSA $0.01 \%$, Taq Polymerase $1 \mathrm{U}$ and template DNA was used. Target sequences were amplified in $25-\mu 1$ reaction volumes (after initial denaturation step at $94^{\circ} \mathrm{C}$ for $2 \mathrm{~min}$ ) for 45 cycles $\left(94^{\circ} \mathrm{C}, 40 \mathrm{~s} ; 55^{\circ} \mathrm{C}, 60 \mathrm{~s}, 72^{\circ} \mathrm{C}, 60 \mathrm{~s}\right)$ followed by a final extension step at $72^{\circ} \mathrm{C}$ for $3 \mathrm{~min}$. Amplified fragments were separated on the A.L.F.-System. Strain relatedness was determined by the cluster analysis software (WinCam ${ }^{\mathbb{B}}$ 2.2) applying the Dice algorithm which considers only band positions, represented by a line diagram. This protocol is also used routinely in this laboratory with a well established record of reproducibility. Reproducibility is checked routinely on the basis of obtaining identical banding patterns when processing different single colonies of the same isolate.

\section{Protein A-gene PCR}

The spa gene coding for protein A contains several different functional regions. To develop a protein Agene PCR protocol two regions within the spa gene were studied, the Fc binding region containing two to five repeat sequences (RS) each $160 \mathrm{bp}$ in size [15], and the X-region containing up to $15 \mathrm{RS}$ with most repeats being $24 \mathrm{bp}$ in size [16]. This region is highly polymorphic with respect to the number and sequence of repeats [16]. Three primers were designed for the selective amplification of the regions within the protein A gene, based on the published sequences for the spa gene [17]: SPA1 (114-(5')-GATTTTAGTATTGCAATACATAATTCG-(3')-140), SPA2 (1702-(5')-CCACCAAATACAGTTGTACCG-(3')-1682) and SPA3 (1088$\left(5^{\prime}\right)$-CTTTGGATGAA(G/A)CC(G/A)TT(G/A)CGTTG $\left.-\left(3^{\prime}\right)-1066\right)$. Primers SPA1 and SPA2 amplify the entire
$\mathrm{RS}$ region (Fc- and X-region), whereas primers SPA1 and SPA3 amplify the RS in the Fc-region only. For this assay a very small number of cells from 24-h colonies grown on Mueller-Hinton agar supplemented with sheep blood $5 \%$ were suspended in $10 \mathrm{mM}$ Tris $/ \mathrm{HCl}(\mathrm{pH} \quad 8.3), 50 \mathrm{mM} \mathrm{KCl}, 2.5 \mathrm{mM} \quad \mathrm{MgCl}_{2}$, $100 \mu \mathrm{mol}$ of each dNTP and $0.4 \mu \mathrm{mol}$ of each primer. After denaturation for $5 \mathrm{~min}$ at $94^{\circ} \mathrm{C}, 3 \mathrm{U}$ of AmpliTaqDNA Polymerase ${ }^{(\mathbb{B})}$ were added followed by another $5 \mathrm{~min}$ at the same temperature (hot start). This was followed by 25 cycles of denaturation at $94^{\circ} \mathrm{C}$ for $20 \mathrm{~s}$, annealing at $55^{\circ} \mathrm{C}$ for $20 \mathrm{~s}$, and extension at $72^{\circ} \mathrm{C}$ for $50 \mathrm{~s}$. The reaction was ended by a final extension at $72^{\circ} \mathrm{C}$ for $5 \mathrm{~min}$. PCR products were separated on an agarose $3 \%$ gel and visualised by ethidium bromide staining. The reproducibility of the method was demonstrated by intra- and inter-assay analyses with three MRSA isolates (strains 119, 267 and 343 from PFGE types 1, 2 and 3, respectively). For the intraassay analyses of variability, these three MRSA isolates were processed 10 times consecutively. During the inter-assay analyses the same three isolates were tested on 10 subsequent days.

\section{$P C R$ to characterise the hyper-variable region (HVR) adjacent to the mecA gene}

Direct repeat units (dru) consisting of up to $10 \mathrm{RS}$ of a 40-bp subunit occur at the $3^{\prime}$ end of the mecA gene. These are followed by a truncated open reading frame (ORF 145) homologous to the amino-terminal part of the glycero-phospho-diesterase Escherichia coli [18]. The insertion sequence IS431 (also called IS257) can be found downstream of this region [18]. The region between the mecA gene and IS431 contains a hypervariable region (HVR) where MRSA isolates may be heterogeneous. Based on the published sequences for the HVR region [19] the following primers were designed: HVR1 (338-(5')-ACTATTCCCTCAGGCGTCC-(3')-358), HVR2 (892-(5')-GGAGTTAATCTACGTCTCATC-(3')-912) and HVR3 (441-(5')CTAAGTAAAATTGCAGATAAGAGG-(3')-464). Two separate PCR reactions were used for the primer pairs HVR1/HVR2 and HVR3/HVR2, respectively. Primer combination HVR1/HVR2 amplified the entire region around dru, whereas primer combination HVR3/HVR2 amplified each RS only. The HVR-PCR was not performed as a multiplex-PCR; instead, two separate reactions with primers HVR1/HVR2 and primers HVR3/HVR2 were performed. For these assays, a very small number of cells from single colonies grown for $24 \mathrm{~h}$ on Mueller-Hinton-Agar supplemented with sheep blood $5 \%$ were suspended in $10 \mathrm{mM}$ Tris $/ \mathrm{HCl}$ (pH 8.3), $50 \mathrm{mM} \mathrm{KCl}, 2.5 \mathrm{mM} \mathrm{MgCl}_{2}, 100 \mu \mathrm{mol}$ of each dNTP, and $0.4 \mu \mathrm{mol}$ of each primer. After $5 \mathrm{~min}$ for denaturation at $94^{\circ} \mathrm{C}, 3 \mathrm{U}$ of AmpliTaq-DNA Polymerase ${ }^{\circledR}$ were added followed by another $5 \mathrm{~min}$ at the temperature (hot start). This was followed by 25 cycles of denaturation at $94^{\circ} \mathrm{C}$ for $30 \mathrm{~s}$, annealing at $58^{\circ} \mathrm{C}$ for $20 \mathrm{~s}$ and extension at $72^{\circ} \mathrm{C}$ for $50 \mathrm{~s}$. The 
reaction was terminated by a final extension step at $72^{\circ} \mathrm{C}$ for $5 \mathrm{~min}$. PCR products were separated on an agarose $3 \%$ gel and visualised by ethidium bromide staining. The reproducibility of the results was demonstrated by intra- and inter-assay analyses with three MRSA isolates (MRSA strains 119, 267 and 343 from PFGE types 1, 2, and 3, respectively). For the intraassay analyses of variability, these three MRSA isolates were processed 10 times consecutively. During the inter-assay analyses the same three isolates were tested on 10 subsequent days.

\section{Coagulase-gene PCR}

The C-terminal end of the coagulase gene, coa, contains four-to-eight RS with a length of $81 \mathrm{bp}$ each. The coa-PCR typing method was based on the use of two primers flanking the RS within the gene. The length of the amplification products depends on the number of RS present in the gene, which may be variable in unrelated isolates. DNA was isolated after cell lysis with lysostaphin and a phenol-chloroform extraction. In a modification of the method for 'nested PCR' described by Goh et al. [5] only primers COAG 2 (5'-CGAGACCAAGATTCAACAAG-3') and COAG 3 (5'-AAAGAAAACCACTCACATCA-3') were used. The amplification protocol was in accordance with the method of Goh et al. [5] and was followed by restriction endonuclease digestion of the fragments with $A l u \mathrm{I}$. Restriction fragments were separated on an agarose $0.8 \%$ gel and visualised by ethidium bromide staining for subsequent analysis with Gel Compar.

\section{Results}

\section{Epidemiology of MRSA from 11 acute hospitals}

Of the $7814 \mathrm{~S}$. aureus isolates referred, $489(6.3 \%)$ were found to be MRSA. MRSA were found in all 11 study hospitals. The proportion of MRSA among clinical isolates from the different hospitals varied from $0.5 \%$ to $7.8 \%$ and was correlated to the bed size of the hospital (Table 1). Hospitals with a greater number of beds had a higher percentage of MRSA and had a greater variation in strain types. The highest percentage $(7.8 \%)$ was found in hospital 1 (1500 beds) and the lowest figure $(0.5 \%)$ was from hospital 11 (200 beds). The incidence of methicillin resistance amongst $S$. aureus referred from intensive care units (ICUs) $(25.5 \%)$ was higher than amongst isolates from other wards within a hospital. The highest incidences of MRSA isolates on non-ICU hospital wards were on surgical (including neurosurgery) wards (13\%) and on internal medicine wards $(6.3 \%)$. The greatest proportion of MRSA were found in bronchial/tracheal aspirates (17.6\%), intra-vascular catheter tips (12.8\%) and throat swabs or sputum $(10.6 \%)$. The distribution of MRSA isolates from other anatomical sites was similar for all clinical departments in each hospital (range $2.5-7.3 \%$ ).

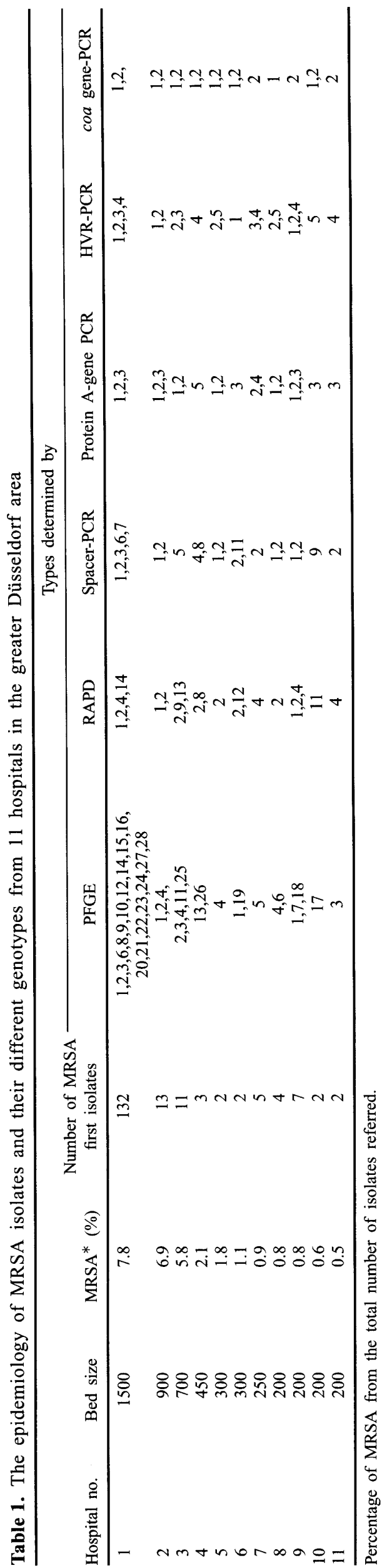




\section{Typing of MRSA from the Düsseldorf area and} the international collection

Molecular typing of the 183 MRSA 'first isolates' from the Düsseldorf area by the six methods described allowed a comparison of the ability of each method to discriminate different strain types. For each method the discriminatory power of the typing system was assessed by counting the number of different strain types detected as a proportion of the total number of isolates. The 183 isolates could be typed by all six methods. The reproducibility of typing patterns was good for all methods with negligible inter-experimental variation.

PFGE distinguished 28 MRSA types. The two most common PFGE types were type 1 and 2 ( 75 and 38 isolates, respectively) that comprised $60 \%$ of all isolates; the remaining PFGE types contained between one and 12 isolates per type (Fig. 1). PFGE type 1 was identical to the North German MRSA epidemic strain which has been associated with MRSA outbreaks in northern Germany including Düsseldorf during the last few years $[8,9]$.

Nine MRSA types were identified by RAPD analysis (Fig. 2). RAPD types 1 and 2 were the most common (113 and 52 isolates, respectively) constituting $90 \%$ of all isolates tested. Only one isolate each belonged to types 8, 9 and 11-14. Fifteen RAPD types were distinguishable from the international strain set by RAPD. Types 1,2 and 4 were also found in the Düsseldorf isolates.
Ten MRSA types were distinguished by $16 \mathrm{~S}-23 \mathrm{~S}$ rDNA spacer amplification (Fig. 3). Spacer types 1 and 2 were the most common (119 and 53 isolates, respectively); they comprised $94 \%$ of all isolates. Only one isolate each belonged to types 5-9 and 11 . Fourteen types were distinguished amongst the international strain collection; six of these types $(1,2,3,5$ and 9) were also observed amongst the Düsseldorf isolates.

Five types were distinguished amongst the 183 MRSA isolates by protein A-gene PCR. These types 1-5 consisted of $92,76,12,2$ and 1 isolates, respectively (Fig. 4). From the set of 91 international isolates, 12 protein-A types were distinguished (Fig. 4) of which five were identical to the Düsseldorf types.

Five types of MRSA were distinguished by HVR-PCR. These types (1-5) consisted of $95,44,20,18$ and 6 isolates, respectively (Fig. 5) and they contained 6, 7, 8,9 and 10 RS, respectively (data not shown). The same five HVR-PCR types were also distinguished amongst the international set of MRSA strains. The discriminatory power of HVR-PCR could be enhanced by subsequent restriction endonuclease digestion. A combination of the restriction endonuclease $A l u \mathrm{I}$ and $R s a \mathrm{I}$ improved the discriminatory power of this technique (data not shown).

Two types of MRSA were distinguished by coagulasegene PCR amplification; all isolates gave only one of two distinct amplification products, A (type 1) and $\mathrm{B}$ (type 2) (Fig. 6). PCR products A and B were found

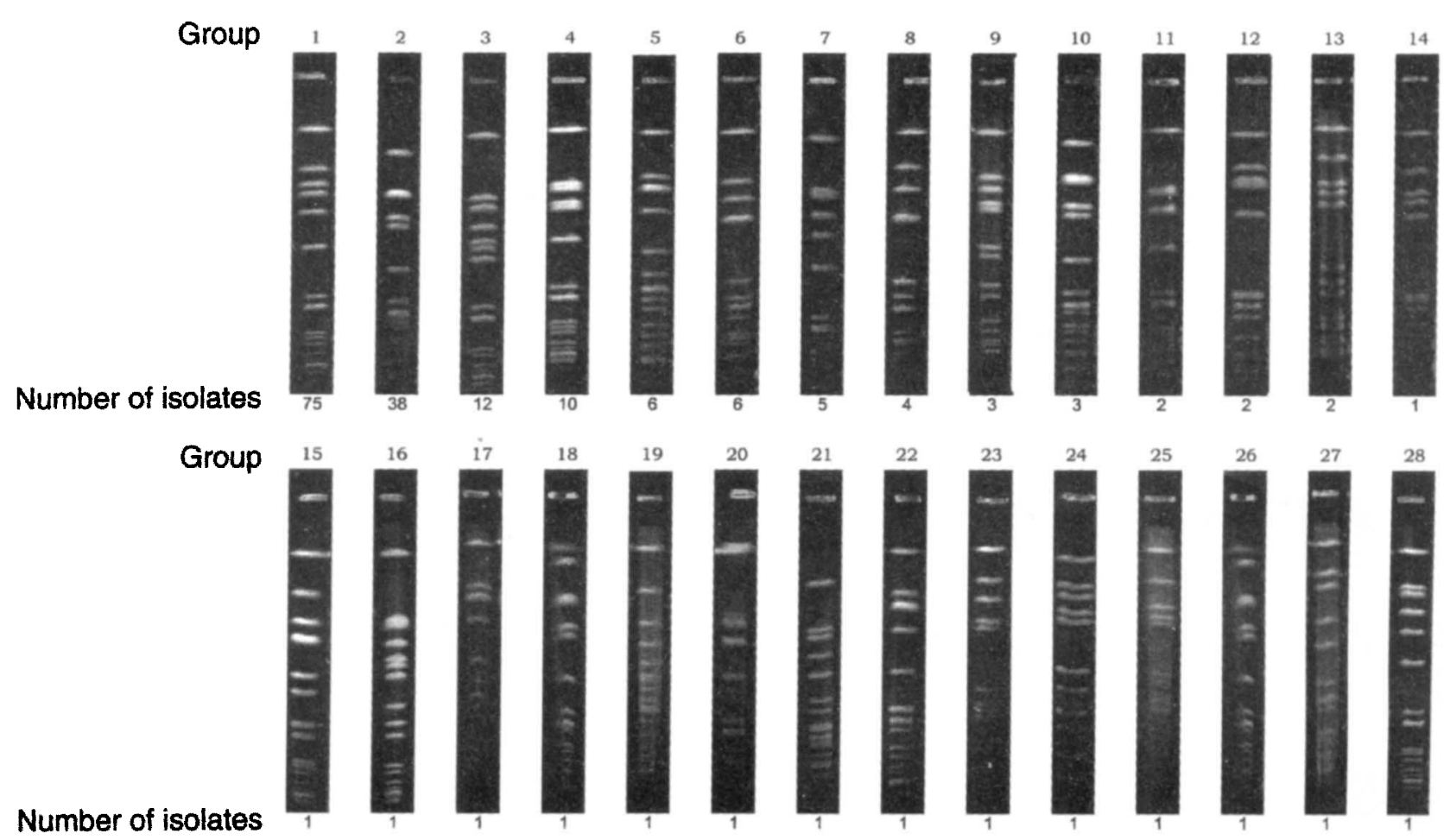

Fig. 1. The 28 different PFGE types and the number of isolates in each type from 183 MRSA isolates. 


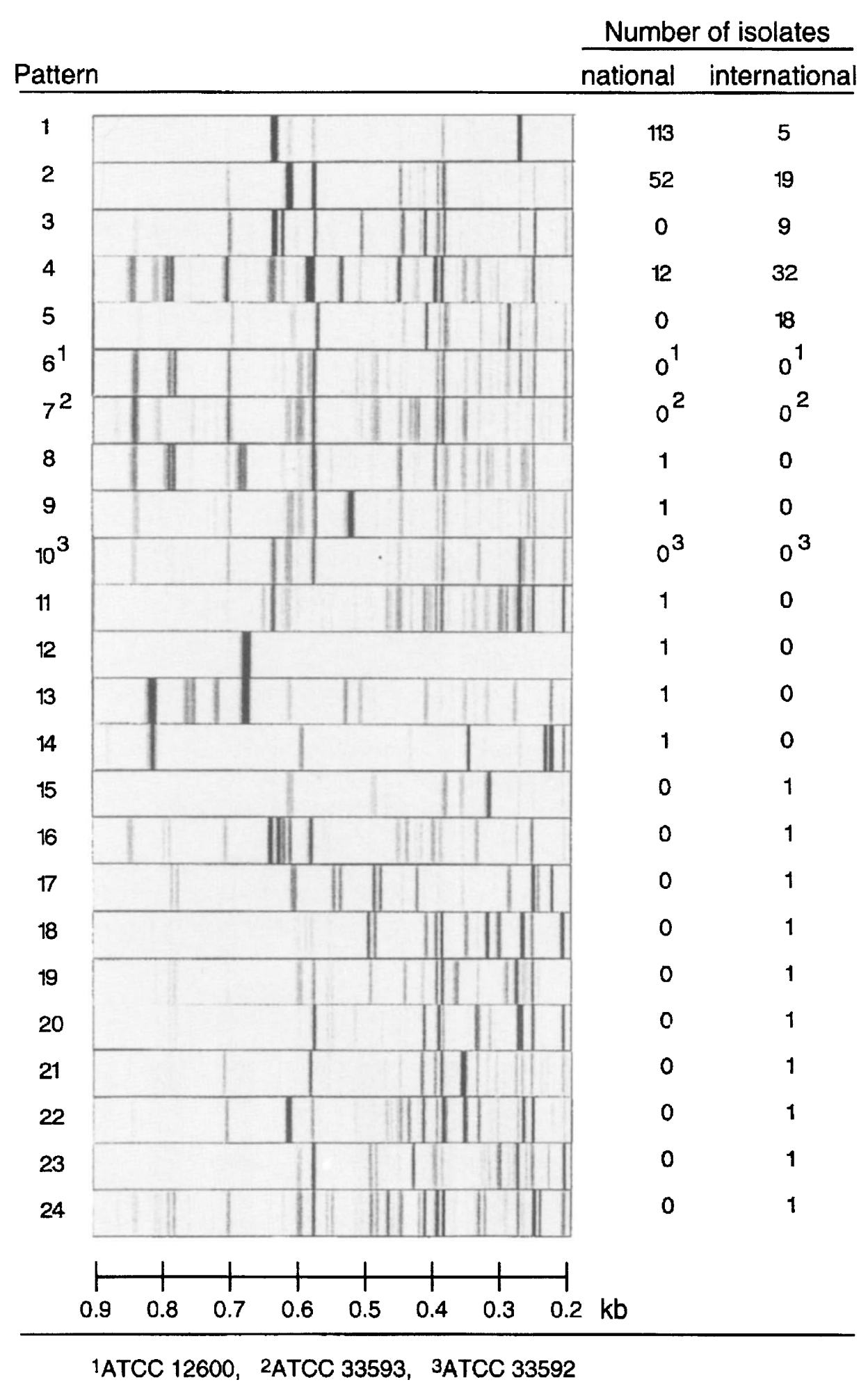

Fig. 2. Overview of different RAPD types from Düsseldorf and international isolates. The distinct banding patterns of three ATCC reference strains used as controls are also shown $\left({ }^{1}\right.$ ATCC $12600,{ }^{2}$ ATCC $33593,{ }^{3}$ ATCC 33592$)$.

with 55 and 128 isolates, respectively. The Alu I restriction endonuclease digest did not improve strain discrimination.

PFGE showed the highest discriminatory power and 28 different types were distinguished amongst the Düsseldorf collection, whereas the discriminatory power of the PCR-based DNA amplification methods described varied from two out of 183 for coa gene PCR to 10 out of 183 for spacer amplification. Thus the discriminatory power of the methods utilised for this investigation was in the following order: PFGE, spacer amplification, RAPD, protein A-gene PCR and HVRPCR, and finally, coa gene PCR. A summary of all types found in each of the study hospitals is shown in Table 1. 


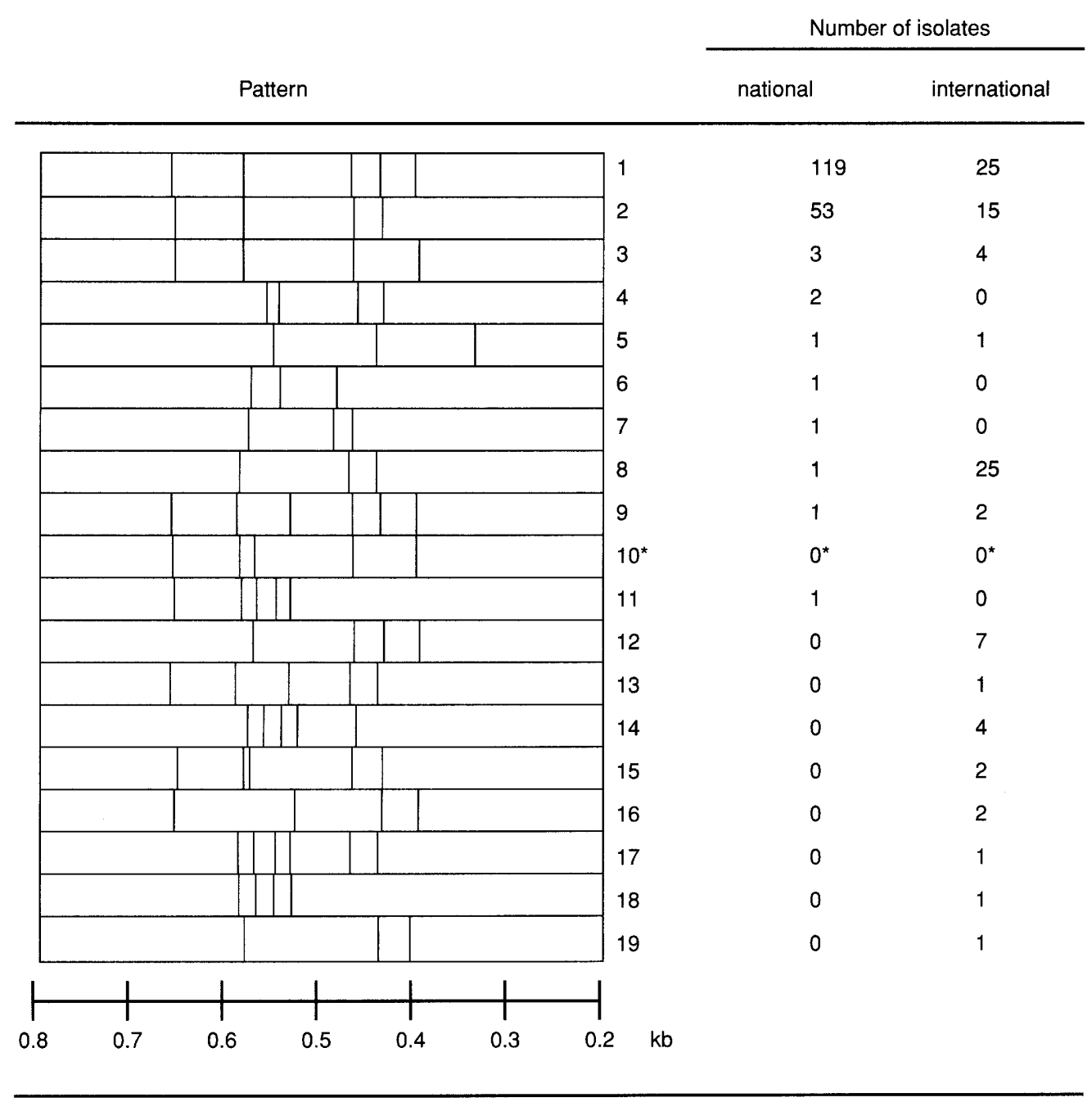

${ }^{*}$ ATCC 12600

Fig. 3. Overview of different $16 \mathrm{~S}-23 \mathrm{~S}$ rDNA spacer types from Düsseldorf and international isolates. ${ }^{*}$ The distinct banding pattern of ATCC reference strain 12600 used as a control is also shown.

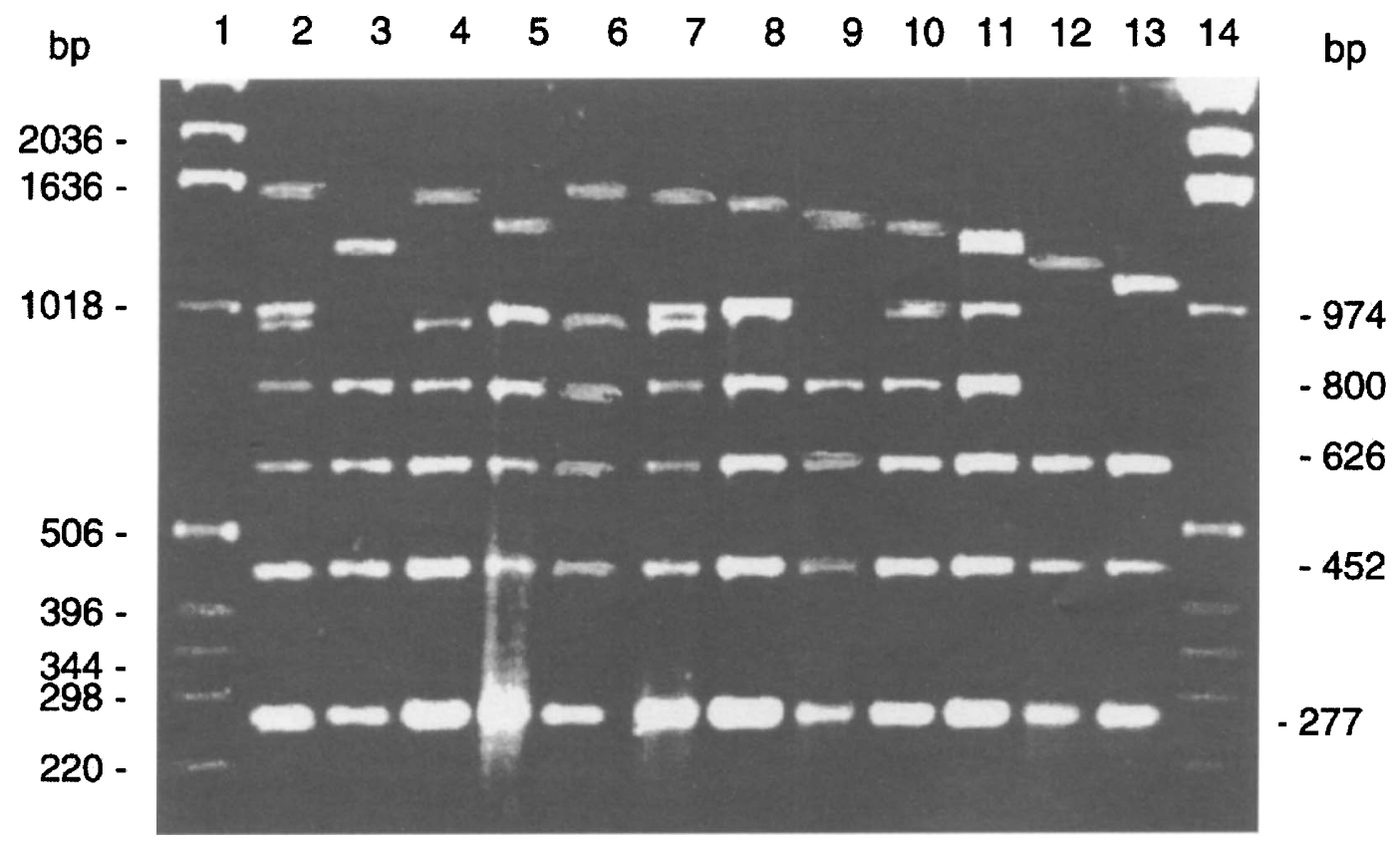

Fig. 4. Protein A-gene PCR typing results of MRSA from Düsseldorf and the international isolates. Lanes 2-6 represent types $1-5$ found in the Düsseldorf strains; $2-13$ represent the 12 types found in the international strain set. Types $1-5$ were identified in both the Düsseldorf and the international strains. Lanes 1 and 14, mol. wt standard markers. 


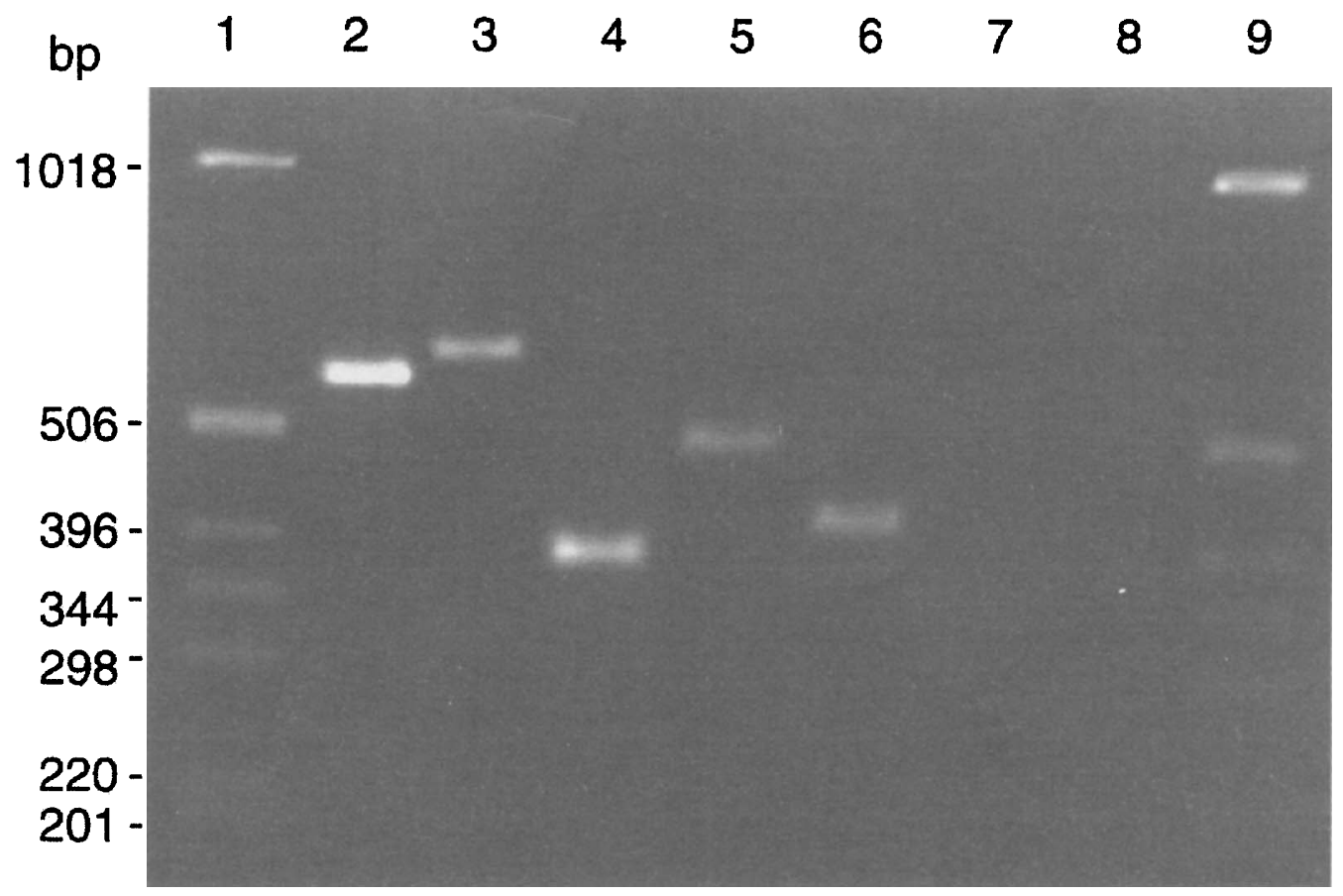

Fig. 5. The HVR-PCR typing results of 183 isolates from Düsseldorf and the international isolates. Lanes 2-6 represent types 1-5 comprising all types found in both the Düsseldorf and international strain collection; 1 and 9 , mol. wt standard markers; 7 and 8 represent controls using $E$. coli DNA and water respectively, ensuring no false amplifications.

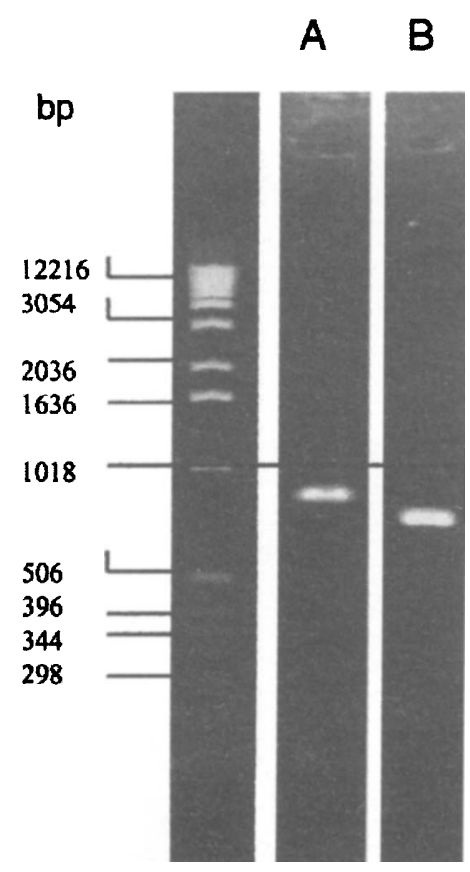

Fig. 6. The coagulase-gene PCR typing results showing two types, $\mathbf{A}(\mathrm{n}=55)$ and $\mathbf{B}(\mathrm{n}=128)$ from the 183 Düsseldorf isolates. Mol. wt markers are shown on the left.

PCR amplification techniques, with the exception of the coagulase-gene PCR, enabled subtypes to be distinguished amongst isolates that were identical by PFGE. For example, 75 of the 183 primary isolates were identified as PFGE type 1 (North German epidemic MRSA strain), and were isolated from four hospitals in the area (Table 1); three RAPD-types (types 1,2 and 4), three spacer-types (1,2 and 3), four HVR-types (types 1, 2, 3 and 4), three protein A gene-types (types 1,2 and 3), and two coagulase gene-types (type 1 and 2) were distinguished amongst these 75 PFGE type-1 isolates. Closer regional analyses of the distribution of subtypes amongst PFGE type 1 revealed, for example, a unique pattern shared by all isolates from hospital no. 6 (PFGE type 1, RAPD type 2, spacer-type 2, protein A gene type 3, HVR-type 1 and coagulase-gene type 1) that was distinct from the remaining isolates of the PFGE type 1 group. Thus, we can speculate that an isolated event of a nosocomial infection involving PFGE type 1 occurred in hospital no. 6, with no exchange of strains with the other hospitals. Also, for example, those isolates of PFGE type 1 from the gastroenterology service in hospital 1 showed a distinct subtype (PFGE type 1, RAPD type 1, spacer-type 2, protein A gene type 3, HVR-type 2 and coagulase-gene type 2) that separated them from the other PFGE type 1 isolates from the same hospital. This shows the benefit of combining typing methods in enhancing the interpretation of results before applying to infection control procedures.

\section{Discussion}

The greatest proportion of MRSA (7.8\%) was found in hospital 1 (1500 beds), the lowest in hospital 11 (200 beds). The epidemiology of MRSA isolates from the 
study hospitals varied in incidence according to hospital size, as has been well documented previously by Panililo et al. [20] during a 17-year observation period (1975-1991). In the present study, the largest hospital (no. 1) showed not only a higher percentage of MRSA but also a greater variation in MRSA types (Table 1). Hospital 1 is considerably larger than all the other study hospitals, with a broader range of patients larger ICUs and more intensive medical care. The higher incidence and number of types of MRSA in this hospital than in the other study hospitals may be attributed to the higher number of patients in special care facilities (e.g., burns units) at risk for MRSA colonisation and infection through extended hospital stay, greater exposure to antibiotics and increased contact with medical personnel. Predictably, the incidence of MRSA on ICUs was higher than in other hospital departments, a pattern reflected throughout Europe, although the overall incidence of MRSA within the Düsseldorf area is $6.3 \%$, a relatively low figure when compared to other European countries [21].

It is widely accepted that DNA-based typing techniques have a greater ability to discriminate between epidemiologically unrelated MRSA strains than traditional phenotypic typing methods [4, 22]. In this comparative investigation of six DNA-based methods to type MRSA isolates from hospitals in the Düsseldorf area, all methods identified two main type groups, accounting for $60-100 \%$ of the isolates tested.

PFGE demonstrated the best discrimination, although this method is the most time consuming of the methods described, taking in excess of $48 \mathrm{~h}$ to obtain a result. Several publications have already confirmed the value of PFGE in $S$. aureus strain-type identification and in discrimination between unrelated clones $[2,4,6,11]$. Because of the ease of comparing the derived banding patterns, its inter-experimental reproducibility and its good discriminatory power, PFGE serves as the 'gold standard' for molecular epidemiological studies of MRSA in our laboratory. However, even with standardised protocols, the inter-laboratory reproducibility of this method is sometimes disappointing [23]. A potential solution may be the introduction of standardised systems (reagent kits, standardised power supply schemes, etc.) and the uniform use of standard control strains and mol. wt markers.

RAPD, with a similar discriminatory power to spacer amplification, was able to subtype isolates that were identical by PFGE (although isolates with identical RAPD patterns could be further subtyped by PFGE). RAPD also has the advantage, as do other PCR-based techniques, of being quick and easy to perform. Whilst this and other studies have shown RAPD to be inferior to PFGE with respect to discriminatory power [24], it is well suited for the routine performance of rapid genotyping and for monitoring the spread of nosocomial staphylococci [25]. A multi-centre study of RAPD showed that in some cases there were major differences between the results of individual laboratories, although this study used standardised DNA samples rather than working from cultured bacteria [25]. Inter-laboratory differences were attributed to the use of different electrophoretic conditions as well as different PCR protocols. Within a laboratory, good reproducibility of RAPD has been well documented when emphasis is placed on the importance of suitable primers and optimising PCR temperature profiles $[25$, 26].

Spacer amplification was the second best method for distinguishing 10 different types in this study. Isolates with identical PFGE patterns could also be further subtyped by this method. It is possible that the discriminatory power might be further enhanced by adding a restriction endonuclease digestion step to this amplification method [27], although this was not included in the study. Spacer amplification banding patterns have also been shown to be highly reproducible and stable over a long period [14, 28]. Potentially confusing results can arise following the cross-hybridisation of amplified DNA with homologous regions within the $16 \mathrm{~S}$ RNA spacer region, resulting in the formation of heteroduplex DNA. These fragments have a lower mobility in the electrophoretic field than their homologous sequences [29]. This was avoided in the present study by using denaturing gel systems and automated sequencing system to analyse single-stranded DNA molecules only.

Protein A-gene PCR was equally as reproducible and easy to implement in the laboratory as was RAPD and spacer amplification. It also allowed further subtyping of isolates with identical PFGE patterns. Frenay et al. [16] showed that discrimination of MRSA isolates by determining the RS number within the $\mathrm{X}$-region is feasible. Also, van Belkum et al. showed that a Danish collection of $S$. aureus of the same lysogroup expressed different numbers of RS within the spa region [30]. They concluded that the X-region is hyper-variable and that the spa region has probably evolved independently from the evolution of the $S$. aureus genome. Whilst repetitive DNA sequences or insertion elements may not be reliable tools with which to measure relatedness, because of their tendency for rapid change, Frenay et al. [16] found the stability of RS in the X-region to be satisfactory. To investigate this, strains of MRSA were subcultured for 3 months and typed by protein A gene-PCR. The number of RS originally present did not change after the 3-month period and they did not vary in 'followup' MRSA isolates from a patient during a 3-year period (data not shown). Frenay et al. [31] postulated that epidemic MRSA isolates have more RS in their $\mathrm{X}$-region than do endemic isolates. In this present study, there was no correlation between the number of RS and the type of isolates. 
HVR-PCR was only able to discriminate five MRSA types similar to protein A-PCR. Some isolates with identical PFGE types showed partially different patterns with HVR-PCR. A similar HVR-PCR method was used by Nishi et al. [32] for the successful typing of Japanese MRSA strains.

Finally, coa gene PCR, the least discriminatory of all the typing methods used, distinguished only two types. Although the coa gene PCR is fast and easy, its limited discriminatory potential means that it cannot be an alternative to the other methods and its usefulness, even for preliminary epidemiological studies, is suspect [5].

The finding that PFGE types can be further subtyped by other DNA-based techniques illustrates that a single technique such as PFGE should not be relied upon to provide an absolute picture of the prevalent genotypes of isolates studied. Isolates of the North German epidemic MRSA strain that was prevalent in the greater Düsseldorf area in recent years have an identical banding pattern by PFGE, but with RAPD, spacer amplification, protein A-gene PCR and HVRPCR, subtypes were identified amongst identical PFGE types. A combination of PFGE plus one of the other PCR-based methods allows a finer degree of resolution in determining the relatedness of MRSA within a hospital. This may have important ramifications for infection control procedures. By comparing the types found in the international MRSA strain collection by RAPD, spacer amplification, protein A-gene PCR and HVR-PCR, with those found in the Düsseldorf strains, a high degree of type homogeneity was observed. This suggests a clonal orgin of MRSA isolates and a high degree of stability of the patterns during the time period 1981-1996.

In summary, PCR-based typing methods are clearly faster and easier to perform, but PFGE is superior in terms of its ability to discriminate between strains. PCR-based methods (especially RAPD and spacer amplification) may be useful for preliminary epidemiological investigation as results are available within $8 \mathrm{~h}$. However, where a cluster of clonally related isolates is suspected, further investigation by PFGE are recommended. Through the combined approach of two techniques, one of which is PFGE, the capability of the laboratory to distinguish between those strains that constitute part of an outbreak and those that are not, can be further enhanced allowing more effective infection control practices to be implemented.

\section{References}

1. Mulligan ME, Murray KA, Ripner BS et al. Methicillin resistant Staphylococcus aureus: a consensus review of the microbiology, pathogenesis, and epidemiology with implica- tions for prevention and management. Am J Med 1993; 94: $313-328$

2. Maslow JN, Mulligan ME, Arbeit RD. Molecular epidemiology: application of contemporary techniques to the typing of microorganisms. Clin Infect Dis 1993; 17: 153-164.

3. Kreiswirth B, Kornblum J, Arbeit RD et al. Evidence for a clonal origin of methicillin resistance in Staphylococcus aureus. Science 1993; 259: 227-230.

4. Tenover FC, Arbeit R, Archer G et al. Comparison of traditional and molecular methods of typing isolates of Staphylococcus aureus. J Clin Microbiol 1994; 32: 407-415.

5. Goh S-H, Byrne SK, Zhang JL, Chow AW. Molecular typing of Staphylococcus aureus on the basis of coagulase gene polymorphism. J Clin Microbiol 1992; 30: 1642-1645.

6. Goering RV. Molecular epidemiology of nosocomial infection: analysis of chromosomal restriction fragment patterns by pulsed-field gel electrophoresis. Infect Control Hosp Epidemiol 1993; 14: 595-600.

7. van Belkum A. DNA fingerprinting of medically important microorganisms by use of PCR. Clin Microbiol Rev 1994; 7: $174-184$.

8. Witte W, Cuny C, Halle E, Wagner J. Methicillin resistance in an epidemic Staphylococcus aureus strain with genomic fingerprints corresponding to those of a sensitive strain in the community. Med Microbiol Lett 1994; 3: 388-395.

9. Witte W, Cuny C, Braulke C, Heuck D. Clonal dissemination of two MRSA strains in Germany. Epidemiol Infect 1994; 113 $67-73$.

10. Deutsches Institut für Normung: Empfindlichkeitsprüfung von Krankheitserregern gegen Chemotherapeutika. In: DINTaschenbuch Medizinische Mikrobiologie und Immunologie. Berlin, Beuth. 1992: 331-406.

11. Tenover FC, Arbeit RD, Goering RV et al. Interpreting chromosomal DNA restriction patterns produced by pulsedfield gel electrophoresis: criteria for bacterial strain typing. J Clin Microbiol 1995; 33: 2233-2239.

12. Bassam BJ, Bently S. DNA fingerprinting using arbitary primer technology (APT): a tool or a torment. Australas Biotechnol 1994; 4: $232-236$

13. Caetano-Anolles G, Bassam BJ, Gresshoff PM. Buffer components tailor DNA amplification with arbitrary primers. PCR Methods Appl 1994; 4: 59-61.

14. Jensen MA, Webster JA, Straus N. Rapid identification of bacteria on the basis of polymerase chain reaction-amplified ribosomal DNA spacer polymorphisms. Appl Environ Microbiol 1993; 59: 945-952.

15. Sakurada J, Li Z, Seki $\mathrm{K}$ et al. Biochemical and genetic heterogeneity of staphylococcal protein A. FEMS Microbiol Lett 1994; 119: 59-63.

16. Frenay HME, Bunschoten AE, Schouls LM et al. Molecular typing of methicillin-resistant Staphylococcus aureus on the basis of protein A gene polymorphism. Eur J Clin Microbiol Infect Dis 1996; 15: 60-64.

17. Uhlén M, Guss B, Nilsson B, Gatenbeck S, Philipson L, Lindberg $M$. Complete sequence of the staphylococcal gene encoding protein A. A gene evolved through multiple duplications. J Biol Chem 1984; 259: 1695-1702.

18. Ryffel C, Bucher R, Kayser FH, Berger-Bachi B. The Staphylococcus aureus mec determinant compromises an unusual cluster of direct repeats and codes for a gene product similar to the Escherichia coli sn-glycerophosphoryl diester phosphodiesterase. J Bacteriol 1991; 173: 7416-7422.

19. EMBL Data library [accession numbers X52594].

20. Panlilio A, Culver DH, Gaynes RP et al. Methicillin-resistant Staphylococcus aureus in U.S. hospitals, 1975-1991. Infect Control Hosp Epidemiol 1992; 13: 582-586.

21. Voss A, Milatovic D, Wallrauch-Schwarz C, Rosdahl VT, Braveny I. Methicillin-resistant Staphylococcus aureus in Europe. Eur J Clin Microbiol Infect Dis 1994; 13: 50-55.

22. Struelens MJ. Consensus guidelines for appropriate use and evaluation of microbial epidemiologic typing systems. Clin Microbial Infect 1996; 2: 2-11.

23. Cookson BD, Aparicio P, Deplano A, Struelens M, Goering R, Marples R. Inter-centre comparison of pulsed-field gel electrophoresis for the typing of methicillin-resistant Staphylococcus aureus. J Med Microbiol 1996; 44: 179-184.

24. Saulnier P, Bourneix C, Prévost G, Andremont A. Random amplified polymorphic DNA assay is less discriminant than pulsed-field electrophoresis for typing strains of methicillin- 
resistant Staphylococcus aureus. J Clin Microbiol 1993; 31: 982-985.

25. van Belkum A, Kluytmans $\mathrm{J}$, van Leeuwen $\mathrm{W}$ et al. Multicenter evaluation of arbitrarily primed PCR for typing of Staphylococcus aureus strains. J Clin Microbiol 1995; 33: 1537-1547.

26. Penner GA, Bush A, Wise $\mathrm{R}$ et al. Reproducibility of random amplified polymorphic DNA (RAPD) analysis among laboratories. PCR Methods Appl 1993; 2: 341-345.

27. Kostman JR, Alden MB, Mair M, Edlind TD, LiPuma JJ, Stull TL. Universal approach to bacterial molecular epidemiology by polymerase chain reaction ribotyping. $J$ Infect Dis 1995 ; 171: 204-208.

28. Dolzani L, Tonin E, Lagatolla C, Monti-Bragadin C. Typing of Staphylococcus aureus by amplification of the 16S-23S rRNA intergenic spacer sequences. FEMS Microbiol Lett 1994; 119: 167-173.
29. Jensen MA, Straus N. Effects of PCR conditions on the formation of heteroduplex and single-stranded DNA products in the amplification of bacterial ribosomal DNA spacer regions. PCR Methods Appl 1993; 3: 186-194.

30. van Belkum A, Riewerts-Eriksen $\mathrm{N}$, Sijmons $\mathrm{M}$ et al. Are variable repeats in the spa gene suitable targets for epidemiological studies of methicillin-resistant Staphylococcus aureus strains? Eur J Clin Microbiol Infect Dis 1996; 15: 768-770.

31. Frénay HME, Theelen JPG, Schouls LM et al. Discrimination of epidemic and non epidemic methicillin-resistant Staphylococcus aureus strains on the basis of protein A gene polymorphism. J Clin Microbiol 1994; 32: 846-847.

32. Nishi J, Miyanohara $\mathrm{H}$, Nakajima $\mathrm{T}$ et al. Molecular typing of the methicillin resistance determinant (mec) of clinical strains of Staphylococcus based on mec hypervariable region length polymorphisms. J Lab Clin Med 1995; 126: 29-35. 